\title{
Changes in the Medical Device's Regulatory Framework and Its Impact on the Medical Device's Industry: From the Medical Device Directives to the Medical Device Regulations
}

\author{
Magali Contardi*
}

\begin{abstract}
Similar to pharmaceutical products, medical devices play an increasingly important role in healthcare worldwide by contributing substantially to the prevention, diagnosis and treatment of diseases. From the patent law perspective both, pharmaceutical products and a medical apparatus, product or device can be patented if they meet the patentability requirements, which are novelty, inventiveness and entail industrial applicability. However, regulatory issues also impact on the whole cycle of the innovation. At a European level, enhancing competitiveness while ensuring public health and safety is one of the key objectives of the European Commission. This article undertakes literature review of the current and incoming regulatory framework governing medical devices with the aim of highlighting how these major changes would affect the industry at issue. The analysis is made in the framework of an on-going research work aimed to determine whether SPCs are needed for promoting innovation in the medical devices industry. A thorough analysis the aforementioned factors affecting medical device's industry will allow the policymakers to understand the root cause of any optimal patent term and find appropriate solutions.
\end{abstract}

Keywords: Medical Device Directive, Medical Device Regulation, regulatory, European Union, reform, innovation, SPCs, policy

\section{The Need for a Regulatory Framework for Healthcare Products}

Medicines and medical devices have been in existence for centuries. According to the literature, there is evidence that scalpels, slings, splints, crutches and other medical devices were used as long ago as 7000 BCE by the Egyptians.

Neither drugs nor medical devices are ordinary consumer products. In most instances, consumers are not in a

\footnotetext{
* Magali Contardi, PhD candidate; Avvocato (Italian Attorney at Law).
}

position to make decisions about when to use them, which to use, how to use them and how to weigh potential benefits against risks as no medicine or device is completely safe. While the concept of ensuring their quality has evolved gradually over time, the modern health products regulation started only after breakthrough progress in the nineteenth century, especially in chemistry, physiology and pharmacology.

Historically, countries have tended to introduce regulation or tighten existing regulation only when forced to do so by a public outcry over an unexpected and unfortunate event. First and foremost, concerns raised over adulterated foods triggered the creation of the Federal Drug Authority (hereinafter 'FDA') in 1906. Although it was not known by its present name until 1930, FDA's modern regulatory functions began with the approval of the 1906 Pure Food and Drugs Act, a law that prohibited interstate commerce in adulterated and misbranded food and drugs. ${ }^{1}$ In 1937, the death of over 100 Americans who had taken a cough mixture containing an antifreeze-type chemical facilitated the introduction of premarket testing to their medicinal regulatory requirements. Later, in the 1960 s, with the thalidomide incident, a tranquilliser and sleeping pills that caused phocomelia in newly born children as a side effect, ${ }^{2}$ the international community has shared consensus that drug, medical technologies and products used in patient care must be subject to stricter regulation than other consumer goods. In fact, however, regulation for medical devices started relatively late, triggered mainly by a major public concern in the 1960s and 1970s regarding the risk of micro-shock from an electrical current via devices connected to patients. ${ }^{3}$ During the 1970 s and 1980 s, demand for stronger regulatory legislation arose

1. W.F. Janssen, 'The Story of the Laws Behind the Labels', 15 FDA Consumer, 32-45 (1981), available at: https://www.fda.gov/downloads/ AboutFDA/History/FOrgsHistory/EvolvingPowers/UCM593437.pdf.

2. Resulting in the shortening or absence of limbs. Helix Magazine, The Thalidomide Tragedy: Lessons for Drug Safety and Regulation (28 July 2009), available at: https://helix.northwestern.edu/article/thalidomidetragedy-lessons-drug-safety-and-regulation (last visited 7 April 2019).

3. M. Cheng, 'HNP brief. No. 8: An Overview of Medical Device Policy and Regulation', World Bank, February 2007 http://wwwwds.worldbank.org/external/default/WDSContentServer/WDSP/IB/ 2007/03/02/000310607_20070302113845/Rendered/PDF/ 388190HNPBrief801PUBLIC1.pdf (last visited 7 April 2019). 
from serious effects caused by intrauterine contraceptive devices (the Dalkon shield and the Copper-7 device) and several brands of tampons. Beginning in the 1970s, countries with a strong medical device industry ${ }^{4}$ initiated the process of either developing or strengthening their regulatory systems. ${ }^{5}$

While in most countries around the world the need for regulation arose primarily to enable patients' access to high-quality, safe and effective medical devices, and avoid access to products that are unsafe, ${ }^{6}$ in Europe the regulatory environment became more stringent mainly to enhance the cohesion of the Single Internal European Market.

Indeed, with the signature of the Treaty of Rome in $1957^{7}$ (hereinafter 'EC' Treaty) a Single Market for the European Union was created, with the aim of, among others, removing barriers to trade within the European Community (EU) Member States. In line with such an objective, Article 30 of the EC Treaty ${ }^{8}$ forbids 'qualitative restrictions on imports and all measures having equivalent effect between Member States', although derogations are allowed, based, inter alia, on grounds of protection of health and life of humans, animals or plants. Therefore, this can only confirm Altenstetter's arguments: ${ }^{9}$ in Europe, regulation of the medical device sector in a harmonised manner would not only ensure patients' access to high-quality, safe and effective medical devices but would also contribute to the smooth functioning of the internal European market, enhancing competitiveness of the Eurozone.

\section{The Medical Device Industry at a Glance}

Pharmaceuticals and medical devices are similar in certain respects: both are health technologies; both can be used to diagnose, treat, alleviate and cure disease; both

4. Among them Canada, United States, Japan and the European Union. These countries nowadays account for close to eighty percent of the medical devices market share. Medtech Europe, Facts and Figures 2018, available at: https://www.medtecheurope.org/wp-content/uploads/ 2018/06/MedTech-Europe_FactsFigures2018_FINAL_1.pdf (last visited 4 April 2019).

5. The role of medical devices and equipment in contemporary healthcare systems and services. World Health Organization. Technical discussion document for the Fifty-third Regional Committee for the Eastern Mediterranean, Agenda item 7 (b), (EM/RC53/Tech.Disc.2), (2006).

6. For instance, this idea was institutionalised in the Medical Device Amendments of 1976 in the United States, manifested in the 2002 Japanese Pharmaceutical Affairs Law as amended in 2005 and partially incorporated in the EU legislation of 1987 creating the single European market, the legal foundation of the medical device framework initiated in the 1990s. C. Altenstetter, 'Medical Device Regulation in the European Union, Japan and the United States. Commonalities, Differences and Challenges', 25 Innovation, 362-88 (2012).

7. Treaty Establishing the European Economic Community (ECC), signed on 25 March 1957 and applied from 1 January 1958, available at: https://eur-lex.europa.eu/legal-content/EN/TXT/?uri=LEGISSUM \%3Axy0023 (last visited 11 March 2019).

8. EC Treaty, Arts. 30-36, Ibid.

9. Altenstetter, above n. 6 require regulatory oversight and a post-market surveillance system; both have intellectual property issues; both need a supply chain; and both have become an integral part of modern healthcare.

The pharmaceutical industry has been economically relevant in the European Union for quite some time; the world pharmaceutical market was worth €934.8 million in 2017. By contrast, the medical device industry has only recently become more visible, reaching a global market value of $€ 360.8$ billion $^{10}$ for the same period. Yet, according to the European Commission, the medical device sector has turned increasingly important for the healthcare of the European Union's citizens, with a market estimated at roughly $€ 110$ billion $^{11}$ in 2016 .

The United States is the largest market for both pharmaceuticals and medical devices, which are estimated to be $48.1 \%$ and $43 \%$ of the global market, respectively. The European pharmaceutical and medical devices market is the second largest, representing $22.2 \%$ and $29 \%$ of the global market, respectively. According to the Medical Devices Sectoral Overview - Galway City and County Economic and Industrial Baseline Study, ${ }^{12}$ the leading European Union medical devices markets are Germany, France, the United Kingdom, Italy and Spain. These top five countries make up $71 \%$ of the European medical devices market, while Germany and France together make up nearly half.

The medical devices industry is highly fragmented, consisting of small niche markets with only a few products. According to the European Medical Device Industry Trade Association (hereinafter 'EUCOMED'), of the approximately 27,000 medical technology companies in Europe, 95\% are classified as small and medium-sized companies. The highest percentage of these is based in Germany, followed by the United Kingdom. After the United Kingdom, the leaders in terms of the number of companies are Italy, Switzerland, France and Spain. The industry includes companies such as Siemens, Hewlett-Packard, Philips and, GE-Healthcare, which operate mainly in electrical-medical equipment, as well as companies such as Boston Scientific and Medtronic, which dominate the implantable device sector. ${ }^{13}$

Owing to their intensive research, ${ }^{14}$ the protection of intellectual property is crucial to preserve the competitiveness of these industries. Indeed, the lack of enforce-

10. Worldwide Medical Devices Forecast 2020 Report, available at: http:// info.evaluategroup.com/rs/607-YGS-364/images/mtwp15.pdf (last visited 9 April 2019).

11. Medtech Europe, The European Medical Technology Industry in Figures 2018, available at: https://www.medtecheurope.org/wp-content/ uploads/2018/06/MedTech-Europe_FactsFigures2018_FINAL_1.pdf (last visited 8 April 2019).

12. J. Cunningham, B. Dolan, D. Kelly, C. Young. Medical Device Sectoral Overview, Galway City and County Economic and Industrial Baseline Study (2015).

13. MDDI Ranking

14. According to the EU Industrial R\&D Investment Scoreboard 2018, the $R \& D$ shares of the health sector - comprising pharmaceuticals and medical devices - accounts for $22 \%$ of the EU R\&D expenditure, available at: https://ec.europa.eu/info/news/2018-industrial-rd-scoreboard-eucompanies-increase-research-investment-amidst-global-technologicalrace-2018-dec-17_en (last visited 6 March 2019). 
ment of Intellectual Property Rights creates disincentives for innovation and prevents companies from recouping their investments in $\mathrm{R} \& \mathrm{D}$. In 2017, medical technology ranked first in patent applications at the European Patent Office, ${ }^{15}$ with 13,134 applications $(6.2 \%+)$, most of which were filed by applicants from the United States (37\%), Japan (9\%) and, among the European countries, Germany (10\%), France (5\%), United Kingdom (3\%), Italy and Spain. In comparison, around 5,534 applications were filed in the same period in the pharmaceutical field, most of them by applicants from the United States, followed by Germany, France and Switzerland.

Any discussion about the regulatory issues around health products in Europe may only start meaningfully if there is clarity about the terms 'medicinal products' and 'medical devices'. Medicinal products refer generally to any substance or combination of substances that may be administered to human beings or animals with a view to making a medical diagnosis or to restoring, correcting or modifying physiological functions in human beings or animals. ${ }^{16}$ A product is classified as a medicinal product on the basis of either its presentation and therapeutic purpose or the type of action exerted by the substance. ${ }^{17}$ By contrast, medical devices overall refer to any apparatus, software, material or other similar or related item intended to be used in the diagnosis, prevention, monitoring, treatment or alleviation of a disease or injury and that does not achieve its principal intended action in or on the human body by pharmacological, immunological or metabolic means. ${ }^{18}$

The foregoing shows that the difference between medicinal products and medical devices lies substantially in the interpretation of the main concepts that define them, namely therapeutic effect and mechanism of action. ${ }^{19}$ Both medical devices and pharmaceuticals (or, more precisely, medicinal products) share the common property of exerting a therapeutic effect, although they are different in regard to their mechanism of action. Medicinal products achieve their principal intended action in or on human bodies by pharmacological, immunological or metabolic means. In contrast, a medical device does not achieve its principal intended action

15. European Patent Office, Annual Reports and Statistics (2017), available at: https://www.epo.org/about-us/annual-reports-statistics/statistics. html\#filings (last visited 15 January 2019).

16. Art. 1(2) of Directive 2001/83/EC of the European Parliament and of the Council of 6 November 2001 on the Community code relating to medicinal products for human use. Official Journal of the European Communities No. L-311/67 of 28 November (2001).

17. The definition of medicinal product was issued originally in Directive 65/65/ECC of 26 January 1965 on the approximation of provisions laid down by law, regulation or administrative action relating to proprietary medicinal products and referred only to the purpose of the product. Official Journal of the European Communities no. P-022 of 9 February (1965).

18. European Union Directive 93/42/ECC concerning medical devices of 14 June 1992. Official Journal of the European Communities No. L-169 of 12 July (1993).

19. M. Racchi, S. Govoni, A. Lucchelli, L. Capone, E. Giovagnoni, 'Insights into the Definition of Terms in European Medical Device Regulation', 13 Expert Review of Medical Devices, 907-17, (2016). in the human body by pharmacological, immunological or metabolic means but may be assisted in its function by such means. Differences such as these justify distinct regulatory regimes.

Developing a new medicinal product or a new use of an existing drug takes a long time; safety and efficacy must be proven before it can be brought to market. This process is enormously expensive because of laboratory, animal and various human trials, as well as high costs of trials needed for regulatory approval. ${ }^{20}$ The most recent analysis by the Tufts Center for the Study of Drug Development estimated the average cost of developing and gaining marketing approval for a new drug at $\$ 2,6$ bn., based on estimated average out-of-pocket costs $(\$ 1,395$ bn.) and the expected returns that investors forego while a drug is in development $(1,163$ bn. $) .^{21} \mathrm{By}$ contrast, the dimension, complexity and function of medical devices vary significantly. Hurdles to proving safety and efficacy differ according to the risk level associated with the use of the medical device: more complex and more invasive devices generally require substantial clinical trials and assessment before approval for market launch is granted, whereas non-invasive and low-risk devices face minimal regulatory hurdles before they can be marketed.

Interestingly, most of the earlier comparative studies on medical device regulatory framework concluded that Europe has been granting faster access to medical technology (e.g. compared with the United States). In a report $^{22}$ John Wilkinson, chief executive of EUCOMED, commented: 'The current European Union regulatory system makes innovative medical technology available to people the fastest in the world while ensuring the highest safety standards.' In line with it, Migliore ${ }^{23}$ argued that many independent studies showed that the path to obtaining regulatory approval works faster in the European Union than in the United States. Further, Hwang et al. ${ }^{24}$ who analysed the regulatory delays for major innovations (e.g. cardiovascular devices), found that, on average, the delay, defined as median time difference between European Union approval marking and the United States approval, is up to 36.3 months in the case of the United States' approval. Academic literature suggests that, compared with

20. J.H. Barton, J.E. Ezekie, 'The Patents-based Pharmaceutical Development Process', 294 JAMA, at 2076 (2005).

21. J.A. DiMasi, H.G. Grabowski, R.W. Hansen, 'Innovation in the Pharmaceutical Industry: New Estimates of R\&D Costs', 47 Journal of Health Economics, 20-33 (2016)

22. J. Wilkinson. EU Regulatory System Brings Europeans Fastest Access to Medical Technology Without Compromising Safety. Eucomed press release (28 January 2011); D. Cohen \& M. Billingsley, European are left to their own devices, BMJ 2011; 342:d2748 doi: $10.1136 / \mathrm{bmj} . \mathrm{d} 2748$ (Published 14 May 2011)

23. A. Migliore. 'On the New Regulation of Medical Devices', 14 Expert Review of Medical Devices, at 921-3 (2017).

24. T.J. Hwang, E. Sokolov E. et al, 'Comparison Rates of Safety Issues and Reporting Trial Outcomes for Medical Devices Approved in the European Union and United States: Cohort Study', 353 BMJ, at i3323 (2016). 
the Japanese market, medical devices in the European Union are available around five years ahead. ${ }^{25}$

\section{Existing Regulatory Framework for Medical Devices}

Regulation of medical drugs and devices involves the competing goals of assuring safety and efficacy while providing rapid movement of innovative products. There are several components of the European regulatory framework that are common to the countries manufacturing the vast majority of medical devices in use today (e.g. Australia, Canada, Japan, the United States and the European Union). These components comprise, at a minimum, ${ }^{26}$ regulatory rules; a governmentapproved regulatory authority (to enforce the rules); one or more conformity assessment bodies (which are accredited by a European Union Member State and which may issue market approval) to assess whether a manufacturer or a device conforms to regulatory requirements; a classification scheme that ranks devices by level of potential risk associated with their use; a quality assurance or management system to ensure compliance of a device with quality standards and norms; a system for evaluating the clinical safety and performance of a device; a system for granting marketing (market entrance) approval for a device that complies with the regulatory rules; and a surveillance system capable of detecting and investigating adverse events associated with the actual use of a device on the market. These elements will now be explained further.

The European Union regulatory system for medical devices is quite young; it is twenty-five years behind the regulation of medical devices in the United States and about twenty-five years behind the European regulation of pharmaceuticals. Factors evidenced before, including differences in the type of industry, the profile for the products, the risk assessments of the products and the approach to generating efficacy and effectiveness data, reflect the difference in regulations for the devices compared with pharmaceuticals: while methods and research protocols for drug safety had been internationally agreed for around twenty-five years, standards, essential requirements, consensus protocols for clinical investigations and common technical specification for medical devices' approval emerged only recently. Yet some components of certain medical devices might be covered by pharmaceutical regulation.

J.P. Boutrand, EU Medical Device Regulatory Framework: Practical Impact of New Regulations, NAMSA White Paper, available at: https:// www.namsa.com/wp-content/uploads/2015/10/WP-EU-MedicalDevice-Regulatory-Framework.pdf (last visited 13 April 2019).

26. World Health Organization, Medical Device Regulations: Global Overview and Guiding Principles (2003), available at: http://www.who.int/ medical_devices/publications/en/MD_Regulations.pdf (last visited 10 April 2019).
Unlike in the case of the United States, which relies on a strictly centralised process through one agency, the FDA, the European medical devices' regulatory framework is synchronised with the regulations of the twentyeight national European Union Members who have considerable discretion in how they enforce compliance with European Law. ${ }^{27}$ Another key difference between these systems is that in the United States, the FDA oversees all regulation of devices. In contrast, the European system confers significant authority on a governmental body and private bodies to oversee device evaluation, market approval and post-market surveillance. For this reason, Chowdhury ${ }^{28}$ defines the European Medical Device regulatory framework as a 'multilevel regulation', in which all the critical aspects of the regulatory life cycle are dispersed across multiple administrative and territorial levels and among both public and private actors.

The formal regulation of devices in Europe began only in the mid-1990s and followed the 'New Approach' concept, introduced for most consumer goods by the European Commission in 1986. This approach is based on the concept of a minimum set of mandatory essential requirements for safety and performance for a product to be sold in the European Union. The approach does not prescribe detailed technical specifications or solutions but promotes the use of voluntary standards (known as 'harmonised standards') that are developed by recognised standards organisations. Products in compliance with harmonised standards benefit from a presumption of conformity and can therefore be marketed throughout the whole European Union area.

Following the new approach, medical devices within Europe have been regulated by means of three directives, namely Directive 90/385/ECC concerning the Active Implantable Medical Devices (AIMDD), Directive 93/42/ECC concerning Medical Devices (MDD) and Directive 98/79/ECC concerning In Vitro Diagnostic Medical Devices (IVDD). ${ }^{29}$

The choice of a directive rather than a regulation as a legal instrument for the regulation of medical devices in Europe denotes that, unlike in the pharmaceutical sector, which is subject to regulations, medical devices have a lower level of harmonisation, since the provisions of the directives have to be written into national law of each Member State. Over the past few years, the system has been subject to amendments and has been complemented by standards and several non-binding technical guidance documents, reflecting the consensus of stakeholders regarding the implementation of the directives. In Europe, governmental regulatory authorities (hereinafter 'Competent Authority') and conformity assess-

27. C. Altenstetter, 'EU and Member State Medical Devices Regulation', 19 International Journal of Technology Assessment in Health Care, 228-48 (2003).

28. N. Chowdhury, European Regulation of Medical Devices and Pharmaceuticals (2014), at 109.

29. Except where otherwise stated, this article focuses on the Medical Devices Directive No, 93/42/ECC, as it is the most comprehensive of the three. 
ment bodies (hereinafter 'Notified Body [ies]') are key players within the medical devices regulatory cycle, each having different responsibilities. Each Member State has its own Competent Authority who acts on behalf of the government to ensure that the requirements of the Medical Device Directives are transposed into the national law of that country. Each Competent Authority is also responsible for the designation and supervision of the conformity assessment bodies, as well as for postmarket surveillance, including the report of adverse incidents of medical devices. Besides the responsibilities cited in rule-making, the Competent Authority also has responsibilities for the approval and monitoring of clinical trials. ${ }^{30}$

Typically, these competences are delegated to bodies such us Ministries of Heath, for instance in Italy, ${ }^{31}$ or an agency within the Ministry, as in the United Kingdom, ${ }^{32}$ Germany $^{33}$ and France. ${ }^{34}$ Despite their being competencies limited to the jurisdiction of the country where these authorities have been created, Competent Authorities participate actively in rule-making activities (e.g. guidance documents) at the European level as well.

Conformity assessment bodies, or so-called notified bodies, are certification organisations tasked with the enforcement of rules; most of them are privately owned and run commercial organisations. Notified bodies are designated and supervised by a European Union country's Competent Authority to assess the conformity of medical devices before being placed on the market. Their primary function is to carry out tasks related to conformity assessment procedures set out in the applicable legislation, which are aimed at demonstrating that the device complies with the requirements of the directive. They are, furthermore, responsible for suspending or withdrawing conformity certificates when they find that a device no longer satisfies the essential requirements set forth in the directives.

The European Commission, through the New Approach Notified and Designated Organisations website (hereinafter 'NANDO'), maintains an up-to-date list of bodies notified by European Union Member States and makes the necessary information available to all interested parties.

Manufacturers seeking approval to place a medical device in the European Union market are free to choose any notified body operating within the European Union, since there is no territorial linkage between the manufacturing site and the location of the notified body. This means that the manufacturer shares a contractual relationship with the notified body in which the former

30. D.B. Jefferys, 'The Regulation of Medical Devices and the Role of the Medical Devices Agency', 52 British Journal of Clinical Pharmacology, 229-35 (2001)

31. Ministero della Salute - Direzione generale dei dispositivi medici e del servizio farmaceutico.

32. Medicines and Healthcare Products Regulatory Agency

33. Bunsdesinstitut für Artzneimittel und Medizinprodukte.

34. L'Agence Nationale de Sécurité du Médicament et des Produits de Santé. chooses the latter to undertake assessment. Critics have argued that a commercial relationship of this kind may compromise public interest. ${ }^{35}$ It is noteworthy that a substantial share of literature shows that although the assessment procedures are the same de jure, there are some variations de facto regarding how notified bodies implement them, ${ }^{36}$ as well as in the way notified bodies are designated and monitored by the relevant Competent Authorities. These disharmonies have resulted in widely differing quality in the performance of existing notified bodies. ${ }^{37}$

Fundamental to the regulation of medical devices in the European Union is the use of a classification scheme to determine the level of control over a device. The classification of the device dictates the appropriate conformity assessment procedure: the higher the classification, the greater the level of assessment required by the notified bodies. This graduation is justified by the fact that medical devices cover wide-ranging products and it is more feasible and economically appropriate to categorise them rather than to subject all to the same rigorous conformity assessment procedure. ${ }^{38}$ Similar schemes are utilised in the United States and other developed countries; however, while the United States has three classes of devices, the European Union and Japan use a fourclass scheme. ${ }^{39}$ More precisely, medical devices in Europe are divided nominatively into three classes, but class II is divided into IIa and IIb with different requirements for each, so that, in essence, the European Union has four classes.

This classification system considers the extent of human vulnerability to a device, as well as criteria concerning the time of uninterrupted contact of the device with the body and the degree of invasiveness. ${ }^{40}$ Class I medical devices pose low risks associated with their use; manufacturers of these devices may declare to the Competent Authority conformity to the marketing requirements without a need to involve a notified body in this declaration. However, they must maintain a prescribed set of technical documentation available for inspection. This assessment procedure is known as 'self-declaration' or 'self-certification' and is described in Annex VII, Mod-

35. It has been contended that the 'individual Notified Bodies will be under commercial pressures to not be perceived as more "difficult" than others' and this may lead to a race towards dilution of oversight. P. Feldschreiber, T. Robinson, PIP and Hips. Do We Need a New Regulatory System for Medical Devices? Lexology (25 July 2012), available at: https://www.lexology.com/library/detail.aspx?g=1e97243d-fb344208-8ecd-86456742fcfd (last visited 18 April 2019).

36. I.C. Santos, G.S. Gazelle, L.A. Rocha, J.M. Tavares, 'Medical Device Specificities: Opportunities for a Dedicated Product Development Methodology', 9 Expert Review of Medical Devices, 299-311 (2014).

37. European Commission, DG Health and Food Safety, DG (Sante) 2017-6255, Overview Report Joint Assessment of Notified Bodies designated under the Medical Devices Directives (2017).

38. E. French-Mowat, B. Joanne, How Are Medical Devices Regulated in the European Union?. 105 Journal of the Royal Society of Medicine, S22-8 (2012).

39. Altenstetter, above n. 6.

40. L.R. Horton, 'Medical Device Regulation in the European Union', 50 Food \& Drug Law Journal, at 461 (1995). 
ule A, EC Declaration of Conformity of the Medical Device Directive. ${ }^{41}$

Approval for more complex devices (classes IIa to III) is directly handled by notified bodies; nevertheless, while the marketing of a class IIa device requires verification only at the production stage, class IIb and III devices are high-risk devices for which the notified body's verification is necessary at both the design and the production stages.

In any case, the conformity assessment procedure for devices falling in classes $\mathrm{IIa}$ and $\mathrm{IIb}$ requires a Full Quality Assurance System (QA), which must comprise the assessment by a notified body of the technical documentation for at least one sample of the device, including the audit of the quality system through the inspection of manufacturers' premises and, when justified, the premises of suppliers and subcontractor.

Class III medical devices must meet the additional requirement of submitting the design dossier to the notified body for approval under audit of the Full Quality Assurance System (Annex II), ${ }^{42}$ and the device must undergo clinical investigations to prove safety as a condition for approval. When clinical trials are involved, the ethics committee must be consulted. After the opinion of an ethics committee has been declared, and at least sixty days before an investigation begins, manufacturers may begin the studies unless notified to the contrary. An annex to the directive contains general requirements for clinical investigations, including requirements for preclinical safety evaluation and protection of human subjects.

It should be noted that, although clinical data are required for high-risk devices, the evidence requirements are vague, not available to the public and nonbinding for manufacturers. Generally, clinical trial is unnecessary for a device that utilises an accepted technology to manage a medical condition for which the technology is an accepted indication of use. For instance, for manufacturers claiming similarity to an existing product, a comparative literature review typically suffices. ${ }^{43}$

The directives call upon the manufacturers, notified bodies and Competent Authorities to exchange information concerning medical device safety; for this purpose the establishment of a European Databank on Medical Devices (hereinafter 'EUDAMED') has been provided for since 1998. This database stores information on manufacturers, data related to approvals and clinical studies and details on post-market events. Despite the good purpose, the utility of EUDAMED has been criticised because so far it has been accessible only to national and European Union authorities; but not to the public. ${ }^{44}$

41. Directive 2001/83/EC, above n. 16.

42. J. Chai, 'Regulation of Medical Devices in the European Union', 21 Journal of Legal Medicine, at 537 (2000)

43. C. Sorenson, M. Drummond, 'Improving Medical Device Regulation: The United States and Europe in Perspective', 92 Milbank Quarterly, at 114-50 (2014).

44. Altenstetter, above n. 27.
When determining whether devices comply with the essential requirements set forth in the directive, notified bodies are expected to rely on national voluntary standards adopted pursuant to the so-called harmonised standards. ${ }^{45}$ The standards are voluntary, and manufacturers, users, certification bodies, public authorities and healthcare professionals participate in their elaboration; many are subsequently adopted or incorporated into international standards by the International Standards Organization (ISO) or included in the so-called guidance documents (hereinafter 'MEDDEV') generated by the European Medical Device Expert Group convened by the European Commission. Notwithstanding their voluntary character, the European Union Medical Devices Directive ${ }^{46}$ offers a powerful incentive for manufacturers to comply with these standards by providing that Member States must presume that devices that conform to standards adopted pursuant to the harmonised standards the references to which have been published in the Official Fournal of the European Communities comply with essential requirements. ${ }^{47}$

A device that meets all the foregoing provisions of the relevant legislation is granted the conformity mark in one Member State. It consists of the initials 'CE', which stand for 'Conformité Européen'. This mark means, among others, that the device can be freely marketed in all the other European Member States and the European Economic Area (EEA) without further controls and no further evaluations. Thus, if, for instance, a German notified body approves the device, then the manufacturer can market it immediately in France, Italy and any other European Union country. This is significantly different from the position for medicinal products, for which market approval is needed in each Member State unless the centralised approval through the European Medicine Agency (EMA) is available.

In the post-marketing phase, manufacturers are required to report all serious adverse events to the Competent Authorities; all that information is further collated into the EUDAMED database. The post-market surveillance comprises both active monitoring of medical devices during their use and the notification to Competent Authorities of those situations that led or have led to serious injury of a patient, user or other person, death of a patient, user or other person; severe deterioration of the state of health of a patient, user or other person; or significant damage of the device. Reporting was voluntary from 1998 until 2011, when it became mandatory for manufacturers to directly report adverse events. 


\section{Political Landscape and the Need for Revision}

While there are agreed European standards for medical devices, the previous decades have witnessed rising concerns that these standards are not uniformly applied. ${ }^{48}$ In the British Medical Fournal, Freemantle ${ }^{49}$ asserted that the current European Union regulatory framework was inadequate to provide enough safeguards for technologies that affect morbidity, mortality and healthrelated quality of life. Eikermann et al. ${ }^{50}$ reached similar conclusions, by highlighting safety issues related to the market authorisation pathway and the need for a more transparent, evidence-based process for medical device approval. Furthermore, as evidenced before, the lack of uniformity in the designation and monitoring of notified bodies among the Competent Authorities has been identified by various scholars as one of the prime reasons for the widely differing quality in the performance of notified bodies. ${ }^{51}$ Such segmentation has undoubtedly led to different levels of health and safety protection and has created obstacles to the internal market.

At the same time, efforts towards harmonisation have been hampered by uncertainties due to regulatory gaps derived from new medical device technology that has been developed in the past years. As Dr. Redberg explains:

In the past 10-20 years the number and complexity of medical devices has exploded ... in contrast to most devices in the $1970 \mathrm{~s}$, the newer products pose substantially greater risks - even life-threatening risks to patients. For example, many new medical devices are permanently implanted in a patient's body and can be moved or changed, if at all, only with great risk to the patient. ${ }^{52}$

In this regard, it is interesting to note that while medical devices historically included software applications with algorithmic calculations and automated functionality, which capabilities resided within the physical medical device, modern software-based medical devices increasingly integrate artificial intelligence (hereinafter 'AI'), ${ }^{53}$

48. D. Cohen, M. Billingsley, 'Europeans Are Left to Their Own Devices', 342 BMJ, at d2748 (2011).

49. N. Freemantle, 'Evaluating and Regulating the Device Industry', 342 $B M J$, at d2839 (2011).

50. M. Eikermann, C. Gludd, M. Perleth, C. Wild, S. Sauerland, I. GutierrezIbarluzea, S.-L. Antoine, J. Demotes-Mainard, E.A.M. Neugebaue, 'Commentary: Europe Needs a Central, Transparent, and Evidencebased Regulation Process for Devices', 346 BMJ, at f2771 (2013).

51. Santos et al., above n. 36.

52. R.F. Redberg, Testimony to Subcommittee on Health, House Committee on Energy and Commerce (17 February 2011), available at: https:// it.scribd.com/document/325129078/HOUSE-HEARING-112THCONGRESS-IMPACT-OF-MEDICAL-DEVICE-REGULATION-ON-JOBSAND-PATIENTS (last visited 19 April 2019).

53. S. Kumba, Al in Medical Devices - Three Emerging Industry Applications, Business Intelligence and Analytics (2019), available at: https:// emerj.com/ai-sector-overviews/ai-medical-devices-three-emergingindustry-applications/ (last visited 19 April 2019). making it possible to reveal patterns in patient records, scanned images or even data stored in mobile phones to improve diagnosis of patients, assist in their treatment and even change something about a medical device without human interaction or by recommending some action to a human recipient who then interacts with the medical device to accept or reject the recommendation. Similarly, wearables and other medical devices produced by general product manufacturers and mobile application (known as 'app') developers have become tremendously popular. These advances, however, challenge the legally defined concepts of a medical device and the associated boundaries of regulation. ${ }^{54}$

Underlining the need to consolidate and simplify the regulatory framework, promote its uniform interpretation across Member States and fill in the regulatory gaps that emerged with regard to a number of new technologies, the Commission initiated in 2008 a fundamental revision of the three Medical Device Directives. ${ }^{55}$

To this end, the Commission conducted two public consultations - one in 2008 and the second one in 2010 - seeking input from industry members, regulatory authorities, professionals and other stakeholders regarding the regulatory system and possible targets for reform. A process for reviewing the medical devices regulatory legislation followed the aforementioned consultations, which was expected to conclude with the draft of the proposals for reform by the beginning of 2012 .

In the meantime, two high-profile incidents that occurred between 2010 and 2012 prompted the Commission to push for the replacement of the former, less restrictive European Union Medical Device Directive with a more stringent system. ${ }^{56}$

In 2010, metal-on-metal (hereinafter 'MoM') hip replacements were recalled because of high failures rates; these implants were originally designed as an alternative in younger osteoarthritis patients, for whom long-term total hip replacement device survival is poor. However, MoM protheses have raised concerns about the release into the body of metals such cobalt and chromium and entry into the bloodstream and soft tissues. ${ }^{57}$ The problem caught the attention of the European Union, where around 100,000 patients have been subjected to MoM hip replacement. Investigations showed that 650 patients were fitted with hip protheses with modifications that had not been approved in the European Union. ${ }^{58}$

54. C.A. Tschider, 'Deus Ex Machina: Regulating Cybersecurity and Artificial Intelligence for Patients of the Future', 5 Savannah Law Review, at 177 (2018)

55. European Commission Directorate for Health and Consumers, Revision of the Medical Device Directives (26 October 2013), available at: www.ec.europa.eu/health/medical-devices/documents/revision/ index_en.htm (last visited 20 January 2019).

56. European Commission Press Release, Medical Devices: European Commission Calls for Immediate Actions - Tighten Controls, Increase Surveillance, Restore Confidence, available at: http://europa.eu/rapid/ press-release_IP-12-119_en.htm (last visited 20 January 2019).

57. D. Cohen, How Safe Are Metal-on-metal Hip Implants? 344 BMJ, at e1410 (2012).

58. D. Cohen, 'Faulty Hip Implant Shows up Failings of EU Regulation', 345 BMJ, at e7163 (2012). 
Similarly, since 2010, potential health concerns have been raised in regard to silicone breast implants manufactured by the French firm Poly Implant Prostheses (hereinafter 'PIP'). In 2012 an unexpectedly large number of women were diagnosed as suffering from ruptured breast implants, leading to the breast implant controversy. The controversy turned into a scandal as PIP has been manufacturing implants using industrial grade silicone. The French government called the women who had received this implant for recall at no cost, but because of poor record keeping women were unable to find out whether they had received these implants or not.

These separate incidents, besides having highlighted the need for strengthening of the European Union Medical Devices Directives, led to a debate on the need for actions to enhance the traceability and long-term monitoring of devices in terms of safety and performance. In a resolution adopted in June 2012, ${ }^{59}$ the European Parliament called for a more stringent surveillance, placing on the market requirements and safety controls, a stronger vigilance system as well as better patient information about the quality of high-risk, implantable devices and the potential risks.

In September 2012 the European Commission finally adopted a proposa ${ }^{60}$ for Regulation on Medical Devices and In-Vitro Diagnostics and submitted the draft for approval to the European Parliament and the Council, which introduced several changes in 2014 and 2015, respectively. ${ }^{61}$ The final text of the two regulations was agreed in 2016 and, after being translated into the official European Union languages, both texts were finally adopted in April 2017. The process concluded with the publication in the Official Journal of the European Union in May $2017^{62,63}$; both regulations became legally binding on 25 May 2017.

59. European Parliament Resolution on Defective Silicone Gel Breast Implants Made by French Company PIP, https://publications. europa.eu/en/publication-detail/-/publication/1b63129f-4e29-11e3ae03-01aa75ed71a1/language-en (last visited 25 January 2019).

60. Commission Proposal for a Regulation of the European Parliament and the of the Council on Medical Devices and Amending Directive 2001/83/EC, Regulation (EC) No. 178/2001 and Regulation (EC) No. 1223/2009, COM(2012) 542; Commission Proposal for a Regulation of the European Parliament and of the Council on In Vitro Diagnostic Medical Devices, $\operatorname{COM}(2012) 541$.

61. L. Hancher, M.E. Földes, 'Revision of the Regulatory Framework for Medical Devices in the European Union: The Legal Challenges', 4 European Journal of Risk Regulation, 429-35 (2013).

62. Regulation European Union 2017/745 on Medical Devices of the European Parliament and of the Council of 5 April 2017. Official Journal of the European Communities No. L-117/1 (2017).

63. Regulation European Union $2017 / 746$ on in vitro diagnostic medical devices and repealing Directive 98/79/EC and Commission Decision 2010/227/EU of the European Parliament and of the Council of 5 April 2017. Official Journal of the European Communities No. L-117/176 (2017).

\section{New Regulations for Medical Devices: Main Changes}

The new regulations promise to introduce a series of extremely important improvements to modernise the current system and to properly address the gaps of the past.

The proposals take the form of a Regulation; unlike directives, which need transposition by national parliaments, regulations are directly enforceable, and stakeholders are accountable under European Union law. It is believed to be the appropriate legal instrument as it imposes clear and detailed rules that will become applicable in a uniform manner at the same time throughout the European Union. Furthermore, since for historical reasons the Active Implantable Device Directive and the Medical Device Directive were regulated in two separate legal instruments, in the interest of simplification, these two directives have been replaced by a single legislative act applicable to all medical devices other than in vitro diagnostic. ${ }^{64}$

Although the new regulations are already legally binding, they will apply three years ${ }^{65}$ after publication in the case of Medical Device Regulation and five years ${ }^{66}$ after publication in the case of In Vitro Diagnostic Device Regulation. This transition period is meant to allow all major stakeholders, including the European Union Commission, Competent Authorities, notified bodies and manufacturers, to meet their respective obligations from the date of application.

While under the new Regulation the classification scheme into four classes has been retained, rules have tightened and changed for some products, and, as a result, some devices will be reclassified to higher classes ${ }^{67}$ For the purpose of the product's classification, the criterion is still the vulnerability of the human body, although the potential risk associated with the technical design and manufacture of the device will also be taken into account. ${ }^{68}$ In addition, some devices lacking medical purpose that were previously exempt from the regulations but that present a high-risk profile are now within the scope of the new legislation. ${ }^{69}$

Interestingly, while the definition of medical devices in the Regulation essentially maintains the legacy of the previous legislation, the 'intended purpose' under the new medical device definition has been broadened to

64.

Recital 5, Regulation European Union 2017/745 on Medical Devices, above n. 62.

65. The Medical Device Regulation will apply as of May 2020.

66. The In Vitro Diagnostic Device Regulation will apply as of May 2022.

67. For instance, active implantable devices and their accessories, devices incorporating nanomaterials, some software devices as well as devices intended specifically for use in direct contact with the heart or central circulatory system will be classified as Class III.

68. Recital 58, Regulation European Union 2017/745 on Medical Devices, above n. 62

69. For instance, it includes aesthetic devices that may not have a medically intended purpose (coloured or non-corrective contact lenses) as well as devices designed for the purpose of 'prediction' of a disease or other health condition. Arts. 1 and 2 Medical Device Regulation, above n. 62. 
include 'prediction' and 'prognosis' of disease and other health conditions. This may bring certain digital healthcare technologies ${ }^{70}$ under the scope of this definition.

The substantive requirements and conformity assessment procedures are more complex and burdensome under the Medical Device Regulation. For instance, the revised text demands more rigorous clinical evidence for class III and implantable medical devices. With only certain exceptions, these categories of devices must go through clinical investigations; equivalence principles as compliance with current MEDDEVs guiding documents on clinical requirements ${ }^{71}$ will in many cases be insufficient to comply with the new rules. In particular, manufacturers will therefore need to conduct clinical investigations ${ }^{72}$ in case they lack sufficient clinical evidence to support the claims done on both safety and performance of a dedicated device, ${ }^{73}$ 'sufficient clinical evidence' being only clinical data produced either by the manufacturer on its own or by the competitor, although in this latter case a contract must be available to justify access to the clinical data. Essentially, under the new Regulation full access to clinical data used to support the safety and performance claim is mandatory in order to satisfy the clinical investigation's requirement.

In line with it, the clinical evaluation procedure for certain high-risk profile devices will need to be carried out under the 'scrutiny' of a newly formed Committee Medical Devices Coordination Group (hereinafter 'MDCG') made up of members appointed by Member States due to their role and experience in the field of medical devices, who will assess the preliminary report of the notified bodies and will eventually review it before granting the 'CE' certification mark. ${ }^{74}$ Justified by the need to harmonise evaluation of high-risk devices on clinical aspects to solve problems experienced in the past, this scrutiny mechanism empowers the authorities to have a 'second look' at individual assessments and make their views known before a device is placed on the market.

The forthcoming changes will undoubtedly represent a huge challenge for manufacturers; however, they might also act as a trigger for implementing an operationalised approach while ensuring consistent high standards. As Altenstetter expressed,

The twenty-year-old system has relied on manufacturers' claims of the performance of high-risk medical devices, but with little input from clinical practitioners and academic scientists. Hence it makes a great deal of sense to give more considerations to clinical data, clinical assessments, and make use of clinicians' experience with patient outcomes. ${ }^{75}$

Nevertheless, (probably) in response to the stakeholders' constant requests of rendering the application of the MDR to legacy products more viable, one step back to the older approach has been taken in this regard. Indeed, on 22 March 2019 the MDCG published a document on the interpretation of Article 54(2)b of the Medical Devices Regulation, which states:

The Clinical evaluation consultation procedure shall not be required where the device has been designed by modifying a device already marketed by the same manufacturer for the same intended purpose, provided that the manufacturer has demonstrated to the satisfaction of the notified body that the modifications do not adversely affect the benefit-risk ratio of the device. ${ }^{76}$

In addition, a post-market clinical follow-up evaluation report (PMCF) and summary of safety and clinical performance is required to be updated annually for class III devices and class IIb implantable devices and at least every two years for class IIa and class IIb non-implantable devices to facilitate the gathering of quality, performance and safety data throughout the device's lifetime. This requirement raised some concerns among stakeholders, who prima facie construed this rule as requiring annual clinical data - in line with the MEDDEV guidance documents applicable in the context of the medical device's directives, namely, as requiring further clinical investigations. Nevertheless, it is worth noting that under the Regulation the definition of PMCF is broad and relates to all types of clinical information, namely vigilance, complaints, technical information and publicly available information; by contrast, clinical follow-up under the umbrella of the directives is very much focused on clinical studies and clinical data. ${ }^{77}$ To enhance transparency within the system, the summary of safety and clinical performance shall be made available via EUDAMED, to which access will now be extended to notified bodies, the MDCG, economic operators (manufacturers, authorised representatives, importers, sponsors), experts and the public, including medical institutions. ${ }^{78}$ The inclusion of data sourced from clinical investigations will become mandatory for new class III or implantable medical devices; the details of these clinical investigations will be stored in a system

70. For instance, digital health apps.

71. Guidance document MEDDEV 2.7/1 Rev.4 on Clinical Evaluation Reports (CER) for Medical Devices, European Commission, DG Internal market, Industry, Entrepreneurship and SMEs.

72. Clinical investigations refer to a systematic investigation involving one or more human subjects, undertaken to assess the safety or performance of a medical device.

73. Art. 49, Regulation European Union 2017/745 on Medical Devices, above n. 62.

74. Arts. 78 and 80, Regulation European Union 2017/745 on Medical Devices, above n. 62.

75. C. Altenstetter, 'US Perspectives on the EU Medical Device Approval System, and Lessons Learned from the United States', 4 European Journal of Risk Regulation, at 443 (2013).

76. Interpretation of Art. 54(2)b of 22 March 2019, Medical Device Coordination Group.

77. Indeed, the notion of PMCF was first introduced in the guidance document on post-market clinical follow-up studies MEDDEV 2.12 rev 2.

78. Arts. 26 and 27, Regulation European Union 2017/745 on Medical Devices, above n. 62 
that is interoperable with the clinical trial database for medicinal products. ${ }^{79}$

In the past, lack of data management has been perceived as a major obstacle to reaching final recommendations on the use of medical devices; and having the chance to access clinical investigation data will facilitate post-market analysis and will give more transparency to the system. ${ }^{80}$ Likewise, the aforementioned centralising measures such as the creation of the Medical Device Co-ordination Group, a central database and more stringent clinical trials seem to demonstrate the legislature's intention towards a medical device's authorisation and monitoring system similar to that currently applying to pharmaceuticals in Europe.

The forthcoming Medical Device Regulation places further responsibilities on the notified bodies, which will be empowered to carry out unannounced inspections of manufacturers and their sub-contractors' sites to check whether they are complying with quality management systems, alongside physical or laboratory tests on devices. Supervision of notified bodies will also change considerably, starting with the requirements that Competent Authorities must apply for a new designation ${ }^{81}$; notified bodies will also be under heightened scrutiny from Competent Authorities as well as under joint assessment with experts nominated by Member States and the Commission. ${ }^{82}$ The proposal also requires rotation of the notified body's personnel involved in the assessment of medical devices at appropriate intervals to strike a reasonable balance between the knowledge and experience required to carry out thorough assessments. Stakeholders ${ }^{83}$ claim that while all these new measures will ensure a more rigorous oversight and uniform performance of the assessment procedures, they might also result in a shortfall of resources owing to the reduction in the number of notified bodies that are going to be renotified. This argument is further supported by the information already available on NANDO, the European Union's notified body database, according to which the number of notified bodies has dropped from about eighty to fifty-nine. ${ }^{84} \mathrm{~A}$ possible shortfall is especially worrisome in the in vitro devices' arena, where about $80 \%$ of products - an estimated 35,200 - will require notified body oversight for the first time. Interestingly, even under the umbrella of the implementation of the current legislative framework, administrative capacities varied greatly across Member States, most of whom

79. S. Milmo, 'New Regulations for Combination Products', 28 Pharmaceutical Technology Europe (2016)

80. Migliore, above n. 23.

81. Art. 29, Regulation European Union 2017/745 on Medical Devices, above n. 62.

82. Art. 35, Regulation European Union 2017/745 on Medical Devices, above n. 62.

83. Medtech Europe, Implementing the New MD and IVD Regulations: Industry Calls for Solutions to Ensure Continuity of Care to Patients (2018), available at: https://www.medtecheurope.org/wp-content/ uploads/2018/07/

MTE_PolicyPaper_MDRIVDRImplementationCallforSolutions_July2018. pdf (last visited 11 April 2019).

84. This number refer to the information available by December 2018 were unable to provide enough skilled manpower capacity for enforcing compliance with the directives. ${ }^{85}$ The revised regulatory framework further includes the introduction of a Unique Device Identification System (hereinafter 'UDI'), ${ }^{86}$ consisting of a series of numerals of an alphanumeric identification code, which will need to be displayed on every medical device to allow the unambiguous identification of a specific device on the market.

The complexity of the UDI system is reflected in the multiple regulatory requirements that it encompasses; it also imposes obligations on all actors of the supply chain, from manufacturers to healthcare professionals, with the involvement of notified bodies and Competent Authorities. The intended result is to improve the traceability of devices throughout the supply chain and thereby help the authorities and manufacturers to take prompt and appropriate actions in response to concerns about device safety.

From a labelling approach, the UDI contains a device identifier (known as 'UDI-DI'), which is an identifier of a device model and is also used as the 'access key' to information stored in the UDI database, such as certificates, declaration of conformity, technical documentation and summary of safety and clinical performance. Furthermore, it comprises a production identifier (known as 'UDI-PI') that identifies the unit of device production. The UDI shall, in addition, be used for reporting serious incidents, and, to support this effort, all the information will be channelled and publicly available via EUDAMED. All stakeholders shall be able to obtain information on the clinical safety performance of a targeted medical device and to track who supplied a medical device and to whom. This is likely to enhance the effectiveness of post-market safety-related activities, in line with the objectives pursued by the reform.

The UDI requirements described in the Medical Device Regulation are completely new for the European Union market - since the Medical Device Directive, which is still in force, has no provisions on the traceability of medical devices and follows the global trend in handling the traceability of medical devices. ${ }^{87}$ In this regard, despite the labelling and operational overhaul that would be required to implement the UDI system, mostly seen as 'cost-prohibitive' and 'technically challenging', it has been reasonably argued ${ }^{88}$ that a globally harmonised approach to UDI is critical to realising the benefits of such a system, is a prerequisite for medical device traceability in a globalised economy and lays the groundwork for the worldwide exchange of medical device data.

85. Altenstetter, above n. 27.

86. Art. 24, Regulation European Union 2017/745 on Medical Devices, above n. 62.

87. Similarly, in the United States, device manufacturers will be required to place a UDI on the device's labels.

88. Global Medical Technology Alliance, Unique Device Identification: Insights and benefits from a single UDI System in the International Arena, White Paper (2018), available at: http://www.globalmedicaltechnol ogyalliance.org/papers/GMTA\%20UDI\%20White\%20Paper.pdf (last visited 23 April 2019). 
In conclusion, one thing is clear: a new regulatory system was necessary to improve the clarity of the regulatory requirements and harmonise the application of regulations across the European Union's Member States. However, this may mean a major overhaul of the European regulatory framework, with the risk that the tougher requirements for the industry lead to a potentially greater timeline to certification, creating disincentives for bringing new medical technologies to the market. ${ }^{89}$

\section{Chief Challenges Resulting from the Regulatory Framework: Would an Extension of the Term of Patent Protection Be Needed for Medical Devices to Promote Medical Device Innovation?}

The World Health Organisation (WHO) defines innovation as a 'process cycle of three major phases that feed into each other: discovery, development and delivery' ${ }^{90}$ Medical device innovation refers not only to the invention of new devices but also to adjustments to, or incremental improvements of, existing devices and clinical practices. In brief, innovation of medical devices must demonstrate added value for patient health.

On the one hand, the apparent nexus between the patent system and economic development, which depicts patents as a lever of industrial progress, has undoubtedly played a role in innovation incentive theory, becoming probably the most quoted argument in favour of (medical device) patents. ${ }^{91}$ Adopting a patent system is thought to encourage investment of resources in making inventions by giving inventors limited monopoly rights in exchange for public disclosure of their invention. On the other hand, however, regulatory issues impact on the whole cycle of the innovation as well. The latter means that the regulatory framework has to be taken into account in the early stages of the medical device design and development, during preclinical and clinical evaluation, product regulatory evaluation, manufacturing and post-marketing surveillance. For this reason, the relationship between medical devices developers and

89. J.J. Howard, 'Balancing Innovation and Medical Device Regulation: The Case of Modern Metal-on-metal Hip Replacements', 2016 Medical Devices, 267-75 (2016).

90. World Health Organization-Intergovernmental Working Group on Public Health, Innovation and Intellectual Property (IGWG). The Global Strategy and Plan of Action on Public Health, Innovation and Intellectual Property (GSPOA), (2008/2009)

91. F. Machlup, E. Penrose, 'The Patent Controversy in the 19th Century', $X$ The Journal of Economic History, 1-29 (1950). the regulatory framework is also critical for innovation and competitiveness in this sector. ${ }^{92}$

In this regard, scholars have empirically found that in relation to pharmaceutical innovations, owing to the entire regulatory bundle, the effective patent life for pharmaceutical innovations, that is, the period between the patent application date and the date when a pharmaceutical is put on the market, is significantly reduced; frequently, at least half the patent term has expired before a product reaches the market. ${ }^{93}$

To cope with this issue, some countries have introduced in their statutes an extension of the patent term by providing a supplementary term of protection for pharmaceutical $^{94}$ inventions. The balance between the exclusive right conferred by patents on innovative pharmaceutical products and the regulatory rules for their marketing approval seem to have been achieved in certain European Union Member States, which started to regulate this matter independently. Lastly, at the European level patent-term extension has been introduced by means of a new title, the Supplementary Certificate Protection (hereinafter 'SPCs'), ${ }^{95}$ to provide a harmonised solution and to deter pharmaceutical R\&D from shifting to nonEuropean markets, e.g. Japan or the United States. ${ }^{96}$

No wonder why while much has been written about extending the patent-term protection in the pharmaceutical field, little has been discussed in relation to SPCs (or analogous title) for medical devices. If the intended purpose of the introduction of such a patentterm extension was to compensate the patentee that has experienced significant regulatory delays in getting its patented pharmaceutical products into the market, at the time that the SPCs regulation was introduced, no lengthy regulatory delays significantly affected medical devices. ${ }^{97}$

The gradual expansion of the medical device regulatory framework has resulted from the complex interaction of various stakeholders' interests, driven by the interest or perspectives of these stakeholders: the industry seeks legal certainty and transparency, and speed to market their devices, while patients and the general public seek access to innovative medical technology at zero risk and in respect of fully tested efficacious products.

92. K.D. Lind, 'Implantable Devices: Regulatory Framework and Reform Options', 130 AARP Public Policy Institute (2017).

93. A study published by the Intellectual Property Institute on 31 August 2007 showed that by 1990 the European effective patent life for pharmaceutical products was between ten and twelve years. D. Curley, Extending Rewards for Innovative Drug Development: A Report on Supplementary Protection Certificates for Pharmaceutical Products (2007)

94. United States in 1984, Japan in 1988, Europe during the 1990s, France and Italy in 1991. T. Rolling, 'How Europe's SPC Regime Works in Practice', 54 Managing Intellectual Property, at 260 (2016)

95. Council Regulation (EEC) No. 1768/92 of 18 June 1992 concerning the creation of a supplementary protection certificate for medicinal products, Official Journal of the European Communities No. L 182 (1992), later updated and replaced by (EC) Regulation No. 469/2009 of the European Parliament and of the Council of 6 May 2009 concerning the supplementary protection certificate for medicinal products, Official Journal of the European Communities No. L 152 (2009).

96. Recitals 6 and 7 of EC Regulation No. 469/2009, Ibid.

97. Migliore, above n. 23 
Nonetheless, the continued overhaul of the regulatory framework of medical devices, culminating with the entry into force of the two new regulations, seems to lengthen the time needed for placing medical devices on the market. At the same time, stakeholders have raised concerns about the more stringent Medical Device Regulation, claiming that it would ultimately result in late access to new technologies and would therefore be linked to human costs. Likewise, some literature contends that regulatory uncertainty leading to longer timelines for the approval process for new medical products may create disincentives for pioneer entry by meaningfully increasing the length of the product development period for novel devices. ${ }^{98}$

Despite the merits of the forthcoming medical device regulatory framework, a notable challenge remains that might hinder medical device innovations in Europe. Evidenced shifts in the regulatory framework for medical technology might result in the erosion of the effective term of patent protection, ${ }^{99}$ leading to undesired market failures and barriers to major medical device innovations. ${ }^{100}$ As has been evidenced, ${ }^{101}$ new innovative medical devices are characterised by a large product heterogeneity and significant uncertainty about the regulatory process itself. This regulatory uncertainty is likely to bring some discouragement into medical device innovation.

At the state of play and by contrast to pharmaceutical innovations, the SPCs legislation does not expressly foresee a medical device to be an eligible product for obtaining an SPC, ${ }^{102}$ and judicial decisions among the European Union jurisdictions have been rather reluctant to grant it. ${ }^{103}$ Sound policy considerations are urgently needed to optimise the existing European Medical Device innovation system. Worth mentioning here is that there is no primary source of law preventing secondary law from amending the term of protection for medical devices. ${ }^{104}$ Nonetheless, for the time being, the

98. R. Guerra-Bretaña, A.L. Flórez-Rendón, 'Impact of Regulations on Innovation in the Field of Medical Devices', 34 Research on Biomedical Engineering, 356-67 (2018).

99. S. Sterckx, Does European Patent Law Unfairly Discriminate Against Medical Devices as Compared with Pharmaceuticals? 25 Expert Opinion on Therapeutic Patents, 845-8 (2015).

100. E. Klar, 'Medical Device Regulation als aktuelle Herausforderung für die rechtssichere Einführung neuer Technologien', 2018 Chirurg, 755-9 (2018).

101. A.D. Stern, 'Innovation under Regulatory Uncertainty: Evidence from Medical Technology', 145 Journal of Public Economics, at 181-200 (2017).

102. A. Hutchinson, N. Fischer, P. Schröler, Is There a Future for Medical Device SPCs? 16 Bio-Science Law Review (2017).

103. Lastly, Court of Justice of the European Union, C-527/2017, Boston Scientific, ECLI:EU:C:2018:867, http://curia.europa.eu/juris/liste.jsf? language=en\&num=C-527/17 (last visited 1 December 2018).

104. Max Planck Institute For Innovation and Competition, Study on the Legal Aspects of SPC - Final Report MPILC (2018), available at: https:// ec.europa.eu/docsroom/documents/29524 (last visited 23 April 2019).

105. 'The scope and sectors covered by the SPC Regulation were decided over 20 years ago. However, in these two decades many of the underlying aspects of the SPC Regulation have changed, among others,
Commission has only timidly introduced this topic on its table for discussions. ${ }^{105,106}$

changes in innovation patterns, big data, bio-medicines, personalised medicines, increasing importance of medical devices as well as changes in marketing authorisation procedures European Commission', European Commission Call for tender: Study on the economic impact of Supplementary Protection Certificates, pharmaceutical incentives and rewards in Europe (2017).

106. Commission Staff Working Document, Summary of the replies to the public consultation on Supplementary Protection Certificates and patent research exemption for sectors whose products are subject to regulated market authorisations, SWD(2018) 242 final, available at: https://eurlex.europa.eu/LexUriServ/LexUriServ.do?uri=SWD:

2018:0242:FIN:EN:PDF (last visited 1 December 2018). 